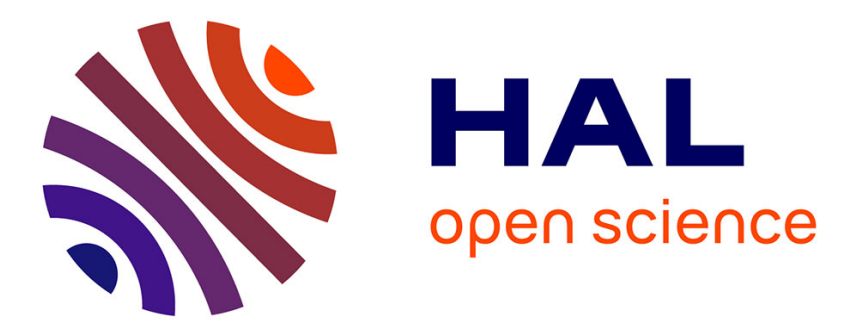

\title{
Luminescent pro-nitroxide lanthanide complexes for the detection of reactive oxygen species
}

Richard Barré, Damien Mouchel Dit Leguerrier, Lionel Fédèle, Daniel Imbert, Jennifer K. Molloy, Fabrice Thomas

\section{> To cite this version:}

Richard Barré, Damien Mouchel Dit Leguerrier, Lionel Fédèle, Daniel Imbert, Jennifer K. Molloy, et al.. Luminescent pro-nitroxide lanthanide complexes for the detection of reactive oxygen species. Chemical Communications, 2020, 56 (3), pp.435-438. 10.1039/c9cc06524e . hal-02874020

\section{HAL Id: hal-02874020 https://hal.science/hal-02874020}

Submitted on 13 Nov 2020

HAL is a multi-disciplinary open access archive for the deposit and dissemination of scientific research documents, whether they are published or not. The documents may come from teaching and research institutions in France or abroad, or from public or private research centers.
L'archive ouverte pluridisciplinaire HAL, est destinée au dépôt et à la diffusion de documents scientifiques de niveau recherche, publiés ou non, émanant des établissements d'enseignement et de recherche français ou étrangers, des laboratoires publics ou privés. 


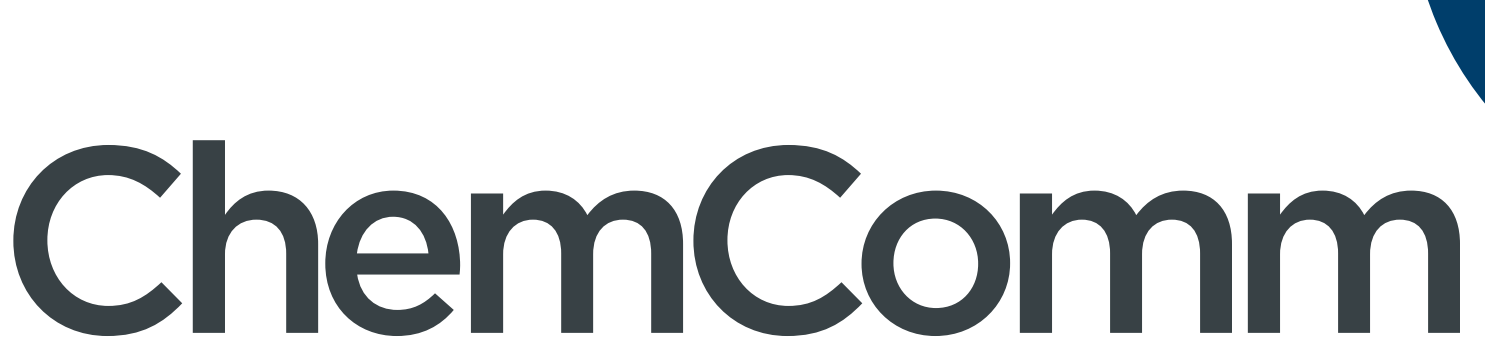

Chemical Communications

\section{Accepted Manuscript}

This article can be cited before page numbers have been issued, to do this please use: R. Barre, D. Mouchel dit Leguerrier, L. Fedele, D. Imbert, J. K. Molloy and F. Thomas, Chem. Commun., 2019, DOI:

10.1039/C9CC06524E.
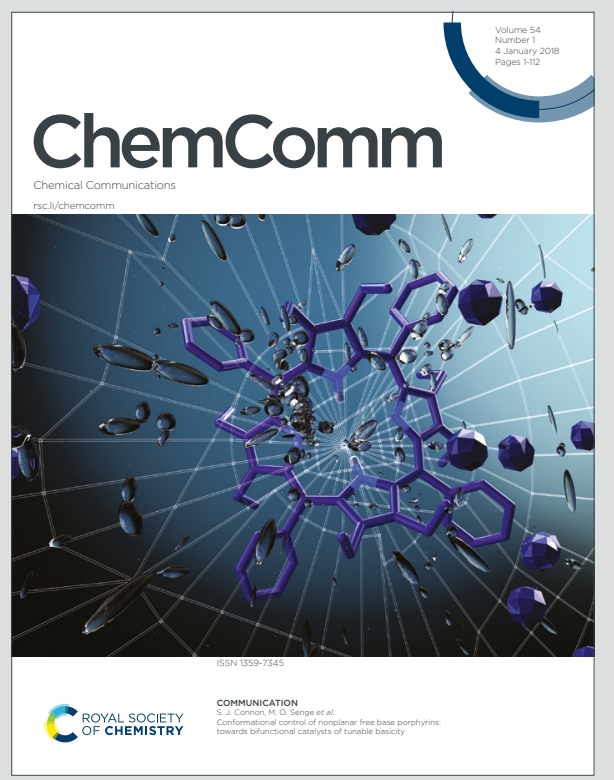

This is an Accepted Manuscript, which has been through the Royal Society of Chemistry peer review process and has been accepted for publication.

Accepted Manuscripts are published online shortly after acceptance, before technical editing, formatting and proof reading. Using this free service, authors can make their results available to the community, in citable form, before we publish the edited article. We will replace this Accepted Manuscript with the edited and formatted Advance Article as soon as it is available.

You can find more information about Accepted Manuscripts in the Information for Authors.

Please note that technical editing may introduce minor changes to the text and/or graphics, which may alter content. The journal's standard Terms \& Conditions and the Ethical guidelines still apply. In no event shall the Royal Society of Chemistry be held responsible for any errors or omissions in this Accepted Manuscript or any consequences arising from the use of any information it contains. 


\section{Luminescent pro-Nitroxide Lanthanide Complexes for the Detection of Reactive Oxygen Species †}

Received 00th January 20xx, Accepted 00th January 20xx DOI: $10.1039 / x 0 x \times 00000 x$
Richard Barré, ${ }^{a}$ Damien Mouchel dit Leguerrier, ${ }^{a}$ Lionel Fedele, ${ }^{b}$ Daniel Imbert, ${ }^{* b, c}$ Jennifer K. Molloy, *a Fabrice Thomas*a
The DOTA-based ligand $\mathrm{H}_{3} \mathrm{~L}(5)$ appended with a pro-nitroxide moiety has been synthesized. The europium and ytterbium complexes $5 \mathrm{Ln}$ show metal-centred luminescence. They reacts with ROS in aqueous media to give a transient iminonitroxide and a stable nitronylnitroxide radical authenticated by EPR, with change in luminescence.

The term reactive oxygen species (ROS) points to a family of molecules which are generated upon incomplete reduction of molecular dioxygen. ${ }^{1}$ For humans, ROS play essential roles in several physiological processes such as signalling and immune response. ${ }^{1,2}$ Their uncontrolled production can however leads to oxidative stress, ${ }^{3}$ which is believed to be at the origin of ageing, ${ }^{4}$ but also major pathologies, including cancers, ${ }^{5}$ diabetes, ${ }^{6}$ neurodegenerative ${ }^{7}$ and cardiac $^{8}$ diseases. The most common ex-vivo detection methods for ROS employ spin traps in combination with EPR spectroscopy ${ }^{9}$ or fluorescence measurements. ${ }^{10}$ The first method is based on the irreversible reaction of short-life radicals $\left(\mathrm{OH}^{*}, \mathrm{O}_{2}{ }^{\circ}\right)$ with a nitrone to produce distinct paramagnetic nitroxide adducts whose stability is sufficient for allowing their detection by EPR spectroscopy. Yet based on a chemical reaction with ROS the second method produce a fluorescent species (switch on) or conversely induces a quenching of the initial fluorescence of the probe (switch off).

The design of new detection methods for ROS is an area of constant development, with applications in the field of physiology and medicine. ${ }^{11,12}$ Few lanthanide complexes have been developped for this purpose. ${ }^{13-22}$ Some are based on a sacrificial reaction with ROS that modulate the energy transfer to the metal ion, ${ }^{16}, 20,21$ while others rely on the distinct sensitization of the metal in the presence of dioxygen. ${ }^{13,15}$ The ROS can be indirectly probed by determining the level of

a. Univ. Grenoble Alpes, CNRS, DCM, F-38000 Grenoble, France. Email: Jennifer.Molloy@univ-grenoble-alpes.fr; Fabrice.Thomas@univ-grenoble-alpes.fr. b. Univ. Grenoble Alpes, CEA, CNRS, INAC-SYMMES, 38000 Grenoble, France c. Univ. Grenoble Alpes, CEA, CNRS, BIG-LCBM, 38000 Grenoble, France † R.B., D. M. d. L. and L. F. contributed equally to this work.

Electronic Supplementary Information (ESI) available: Details synthetic protocols and characterizations. See DOI: 10.1039/x0xx00000x gluthation ${ }^{19}$ or monitoring the redox status. We recently designed lanthanide complexes incorporating redox-active phenolate groups as such reporters. ${ }^{23-25}$ The starting complexes exhibit the narrow emission bands typical of $f$ elements, with long half-life of the excited states and the possibility to tune the wavelength of the emission, both being advantageous in biomedical imaging. ${ }^{26}$ The oxidation of the coordinating phenolates into phenoxyl radicals results in a quenching of the lanthanide-based luminescence, which reaches $90 \%$ in some instances, allowing for a sensitive detection. ${ }^{23-25}$ Following our continuous interest in using proradical lanthanide complexes to monitor oxidative redox events we herein report an alternative approach based on the trapping of $\operatorname{ROS}^{14,16,17,20,21,27-29}$ by $\alpha$-iminohydroxylamine/ $\alpha$ aminonitrone-appended ligands (5, Scheme 1 and 2) coordinated to $\mathrm{Eu}^{\prime \prime \prime}$ and $\mathrm{Yb}^{\mathrm{III}}$ ions. The starting complexes exhibit a sizeable lanthanide-based luminescence and no EPR signal at room temperature. Upon reaction with $\mathrm{OH}^{\bullet}$, lanthanide-nitroxide radical complexes are formed. They are easily detected by EPR spectroscopy and experience quenching of the metal-centered luminescence.

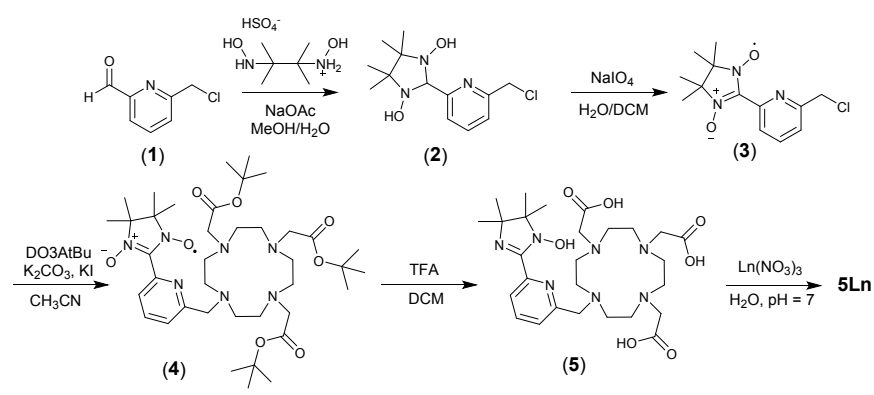

Scheme 1. Simplified synthetic route towards the lanthanide complexes ( $\mathrm{Ln}=\mathrm{Eu} \mathrm{u}^{\mathrm{II}} ; \mathrm{Yb}^{\prime \prime \prime}$ )

The synthesis of ligand $\mathbf{5}$ is based on the coupling of a pyridinenitronyl nitroxide conjugate $\mathbf{3}$ with the tris-protected DOTA derivative (DO3AtBu: 1,4,7- tris(tert-butoxycarbonylmethyl)1,4,7,10-tetraazacyclododecane), followed by deprotection with TFA, as depicted in Scheme 1. The precursor $\mathbf{3}$ is prepared in two steps from the 6-(chloromethyl)-pyridine-2- 
carboxaldehyde (1) by condensation with 1,1',2, $2^{\prime}-$ tetramethylethylenebis(hydroxylamine) to afford 2 (Fig. S1, S2), followed by oxidation with $\mathrm{NaIO}_{4}$. Nucleophilic substitution on the DO3AtBu and subsequent deprotection with TFA affords 4 in a total yield of $84 \%$. The ligand 5 (Fig. S4-S7) was characterized by ${ }^{1} \mathrm{H} /{ }^{15} \mathrm{~N}$ HMBC in $\mathrm{D}_{2} \mathrm{O}$. It shows two ${ }^{15} \mathrm{~N}$ resonances at $132 \mathrm{ppm}$ and $185 \mathrm{ppm}$, which are assigned to the imine and hydroxylamine, based on similarity of chemical shifts with the bis(hydroxylamine) $\mathbf{2}$ (Fig. S3,S8). ${ }^{30,31}$

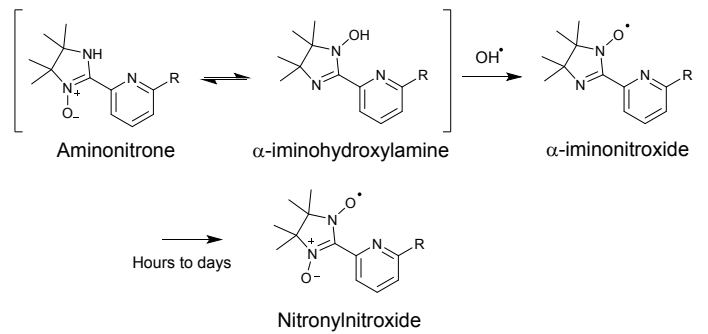

Scheme 2. Tautomeric forms of the pro-nitroxide unit and its reaction with $\mathrm{OH}^{*}$

This demonstrates that the pro-radical unit is best described as a $\alpha$-iminohydroxylamine rather than the aminonitrone tautomer (scheme 2). The ligand was next metallated by the appropriate lanthanide salt $\left(\mathrm{Eu}^{3+}, \mathrm{Yb}^{3+}\right)$ to give $\mathbf{5 E u}$ and $\mathbf{5 Y b}$, respectively. The mass spectra of $\mathbf{5 E u}$ and $\mathbf{5 Y b}$ (Fig. S10, S11) show the expected molecular peaks for the formation of complexes with 1:1 (M:L) stoichiometry. Both complexes are paramagnetic due to the lanthanide ion but do not show EPR resonance at $298 \mathrm{~K}$ due to the fast relaxation of the metal.

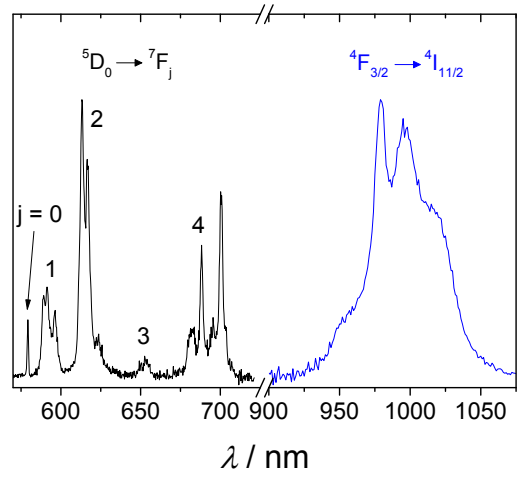

Figure 1. Normalized emission spectra $\left(\lambda_{\text {ex }}=325 \mathrm{~nm}\right.$ ) of (black) $\mathbf{5 E u}$ and (blue) $\mathbf{5} \mathbf{Y b}$ in $0.03 \mathrm{M}$ aqueous solution and $T=293 \mathrm{~K}$.

Complexes $\mathbf{5 E u}$ and $\mathbf{5} \mathrm{Yb}$ proved to be luminescent in the visible and NIR region, respectively, as depicted in Fig. 1 . The emission spectrum of 5Eu (black line) deserves specific comments since it is sensitive to the metal ion environment. Thus, upon excitation in the ligand ${ }^{1} \pi \pi^{*}$ state at $293 \mathrm{~K}$, the emission spectrum displays the characteristic Eu $\left({ }^{5} \mathrm{D}_{0} \rightarrow{ }^{7} \mathrm{~F}_{J}, J=\right.$ $0-4)$ transitions. The ${ }^{5} D_{0} \rightarrow{ }^{7} F_{0}$ transition, which is unique for a given chemical environment, displays an intense and fairly symmetrical main band at $17265 \mathrm{~cm}^{-1}$ (Fig. S14) that is reminiscent of a site within a $C_{n}$ (or $C_{n v}$ ) symmetry. This spectrum may be interpreted in terms of a low-symmetry around Eu'I', derived from a higher pseudo tetragonal symmetry. The transition to ${ }^{7} F_{1}$ displays three components with a total splitting of $193 \mathrm{~cm}^{-1}$. The two components appearing at low energy can be thoughPbsoarishing splitting $\left(57 \mathrm{~cm}^{-1}\right)$ of the ${ }^{7} \mathrm{~F}_{1}\left(\mathrm{E}_{\mathrm{g}}\right)$ sub-level in tetragonal symmetry induced by the distortion of the coordination polyhedron. The ${ }^{5} \mathrm{D}_{0} \rightarrow{ }^{7} \mathrm{~F}_{2}$ transition displays three bands close in energy. The emission spectrum is dominated by this transition, as expected for a low symmetry around the Eu"l' ion. Interestingly, the ${ }^{5} \mathrm{D}_{0} \rightarrow{ }^{7} \mathrm{~F}_{4}$ transition shows only five components. The luminescence data can be further used to calculate the number of co-ordinated water molecules $q$ in the coordination sphere of Eu'll using the emission lifetimes (analyzing wavelength sets on the maximum of the ${ }^{5} \mathrm{D}_{0} \rightarrow{ }^{7} \mathrm{~F}_{2}$ transition) in $\mathrm{H}_{2} \mathrm{O}$ and $\mathrm{D}_{2} \mathrm{O} \quad(0.57(1)$ and $1.04(2) \mathrm{ms}$, respectively). Empirical correlations have been indeed established..$^{32}$ A refined equation 1 proposed for complexes of Eu'll in water with $q \leq 1$ and reevaluated for the absence of alcoholic $\mathrm{O}-\mathrm{H}$, amine $\mathrm{N}-\mathrm{H}$ and amide $\mathrm{N}-\mathrm{H}$ oscillators in the first coordination sphere of Eu'll has been used.

$$
\begin{aligned}
& q=1.11\left(\Delta k_{\text {obs }}-0.31\right) \\
& \text { where } k_{\text {obs }}=1 / \tau_{\text {obs }}, \Delta k_{\text {obs }}=k_{\text {obs }}\left(\mathrm{H}_{2} \mathrm{O}\right)-k_{\text {obs }}\left(\mathrm{D}_{2} \mathrm{O}\right)
\end{aligned}
$$

For $5 \mathrm{Eu}$ we calculated a $q$ value of 0.5 . We ruled out the possibility that this half integer value originates from a mixture of complexes (with and without coordinated water), since the luminescence decay is perfectly monoexponential. We instead hypothesize that one water molecule is either coordinated to the metal and immobilized by hydrogen bonding interactions or it is present in the second coordination sphere close to the hydroxylamine. ${ }^{33}$ Finally, the luminescence spectrum of the ytterbium complex $\mathbf{5} \mathbf{Y b}$ displays a classical metal-centered multiline pattern in the NIR range $949-1030 \mathrm{~nm}$, which is assigned to the ${ }^{4} \mathrm{~F}_{3 / 2} \rightarrow{ }^{4} \mathrm{I}_{11 / 2}$ transition. Altogether these results for $\mathbf{5 E u}$ and $\mathbf{5 Y b}$ confirm that the pronitroxide appended pyridine moiety acts as an antenna for sensitizing $f$-metal ions, whatever their emission range (visible and NIR).

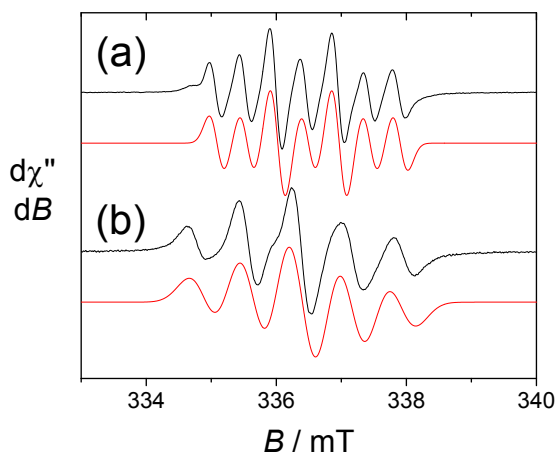

Figure 2. Isotropic EPR spectra of $5 \mathrm{Yb}(0.03 \mathrm{M})$ in the presence of $10 \mathrm{mM} \mathrm{H}_{2} \mathrm{O}_{2}$ and 1 $\mathrm{mM} \mathrm{FeSO}_{4}$ in $\mathrm{H}_{2} \mathrm{O}$. After (a) $10 \mathrm{~min}$; (b) 6 days. Microwave power $1.7 \mathrm{~mW}$, Freq. 9.42 $\mathrm{GHz}$; Mod. Freq. $100 \mathrm{KHz}$, Amp. $0.2 \mathrm{mT}$. $T=293 \mathrm{~K}$. The black lines represent the experimental spectra, the dotted lines the simulated spectra.

We next examined the ability of the complexes $\mathbf{5 E u}$ and $\mathbf{5} \mathbf{Y b}$ to react with the most unstable and toxic ROS, the $\mathrm{OH}^{\bullet}$ radical. ${ }^{34}$ The hydroxyl radical was generated by using a classical Fenton system (aqueous $\mathrm{FeSO}_{4}$ in the presence of $\mathrm{H}_{2} \mathrm{O}_{2}$ ) and the reaction was monitored by EPR spectroscopy in aqueous media (Fig. 2, 3 and S16-S30). During the first minutes we 
observed the growth of a seven-line pattern of intensity 1:1:2:1:2:1:1 (Fig. 2). This signal reached its maximum intensity at about 30 minutes (Fig. 3), after which it slowly decreased (hour to day time scale). It could be simulated by considering the coupling of the electron spin with two inequivalent ${ }^{14} \mathrm{~N}$ nucleus and the hyperfine coupling (HFC) constants 13 and 25 $\mathrm{MHz}$. The overall shape of the spectrum and the measured HFC unambiguously show the pro-radical unit is converted into an $\alpha$-iminonitroxide moiety (scheme 2 ) $^{35,36}$ upon reaction with the hydroxyl radical.

Interestingly, the $\alpha$-iminonitroxide is not the only species that forms upon reaction with the hydroxyl radical $\mathrm{OH}^{\circ}$. After one hour new features are detected, which increase in intensity at the expense of the initial $\alpha$-iminonitroxide signal. This supports the formation of a new radical of a higher stability (no decay after two days, Fig. 3). The spectrum obtained after 2-6 days shows that this new radical, of violet color, exhibits a five-line pattern with intensity ratio 1:2:3:2:1 (Fig. 2b). From spectral simulations the HFC constant with two equivalent ${ }^{14} \mathrm{~N}$ nucleus was determined at $21 \mathrm{MHz}$, which is reminiscent of nitronyl nitroxide radicals (scheme 2, Fig. 2b, S12). ${ }^{36}$ The formation of a nitronyl nitroxide radical is also supported by the appearance of a peak at $\mathrm{M}+16$ in the electrospray mass spectrum after the workup (Fig. S15). ${ }^{37}$
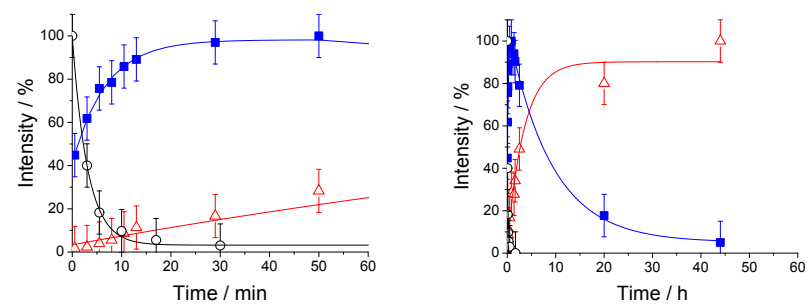

Figure 3. Evolution of the normalized maximum intensity of the EPR signal as a function of time for a $0.03 \mathrm{M}$ solution of $5 \mathrm{Eu}$ (solid blue squares: iminonitroxide radical; open red triangles: nitronyl nitroxide radical) and $0.05 \mathrm{M}$ solution of DMPO (0.05 M, open black circles) in the presence of $10 \mathrm{mM} \mathrm{H}_{2} \mathrm{O}_{2}$ and $1 \mathrm{mM} \mathrm{FeSO}_{4}$ in $\mathrm{H}_{2} \mathrm{O}$. Microwave power $1.7 \mathrm{~mW}$, Freq. $9.42 \mathrm{GHz}$; Mod. Freq. $100 \mathrm{KHz}$, Amp. $0.2 \mathrm{mT} ; T=293 \mathrm{~K}$.

We further investigated the reactivity of the complexes with two other radical ROS: The $\mathrm{CH}_{3}{ }^{\circ}$ radical (formed by using the same Fenton system completed by DMSO, Fig. S22) and the superoxide radical $\mathrm{O}_{2}{ }^{--}\left(\mathrm{KO}_{2}\right.$ in excess, Fig. S23). In both cases the intensity of the EPR lines was weak, and showed only the features of the $\alpha$-iminonitroxide radical before quenching. Hence complexes $\mathbf{5 E u}$ and $\mathbf{5 Y b}$ seems to react preferentially with the $\mathrm{OH}^{*}$ radical. Interestingly, both $5 \mathrm{Eu}$ and $\mathbf{5 Y b}$ react with $\mathrm{H}_{2} \mathrm{O}_{2}$, affording the nitroxide radicals, in a somewhat lower yield than in the full Fenton system (Fig. S24-S25). It is indeed known that $\mathrm{OH}^{*}$ can be, in some instances, generated solely from hydrogen peroxide $\left(\mathrm{H}_{2} \mathrm{O}_{2}\right)$ activated either by hydroxylamines ${ }^{38}$ or light exposure. ${ }^{39}$

These encouraging results prompted us to investigate the effect of the metal ion on the reactivity with $\mathrm{OH}^{\bullet}$. We first investigated the reactivity of the free ligand $\mathbf{5}$ within the frame of the Fenton system. No radical could be detected in this case, which is ascribed to the chelation and then "deactivation" of the iron by the macrocycle $\mathbf{5}$. This hypothesis is corroborated by an absence of an EPR signalwwhen the reaction is conducted with the complex pthe presence of 5442 equiv. of DOTA, which acts as free iron scavenger (Fig. S26). On the other hand complexes $\mathbf{5 E u}$ and $\mathbf{5 Y b}$ react similarly, in terms of structure of the radicals formed. The reaction proceeds slightly faster in the case of $\mathbf{5 Y b}$ (Fig. S27, Table S1). Hence the metal ion must be present in the cavity but its nature does not appear to be a key determinant in the reaction.

The potential of $\mathbf{5 E u}$ and $\mathbf{5} \mathbf{Y b}$ to react with $\mathrm{OH}^{\bullet}$ was finally compared to that of the well-known spin trap DMPO. ${ }^{9}$ Under our experimental conditions the signal of the DMPO-OH' adduct decayed rapidly, to give less than $1 \%$ of the initial signal intensity after $1 \mathrm{~h}$ (Fig. S28). In the case of $\mathbf{5 E u}$ and $\mathbf{5 Y b}$ the intensity was still $>95 \%$ of the initial one after one hour ( $\alpha$ iminonitroxide radical). Hence complexes $\mathbf{5 E u}$ and $\mathbf{5} \mathbf{Y b}$ proved to be superior to DMPO in terms of the stability of the generated radical (Fig. 3).

Finally, the final reaction products in the Fenton system were analyzed by luminescence. Upon excitation in the ligand ${ }^{1} \pi \pi^{*}$ state the metal-centred luminescence was still observed. The spectra display the same features arising from the $\mathrm{Eu}\left({ }^{5} \mathrm{D}_{0}\right)$ and $\mathrm{Yb}\left({ }^{2} \mathrm{~F}_{5 / 2}\right)$ electronic levels and similar relative corrected intensities as the starting material (Fig. S31-34). The lifetimes for $\mathbf{5 E u}$ are comparable before and after reactivity with $\mathrm{OH}^{*}$ (0.57(1) and 0.58(1) ms, respectively). These virtually identical data are consistent with a single main environment for the metals in the complexes which is preserved after reaction with the hydroxyl radical $\mathrm{OH}^{\circ}$. However, the intensity of luminescence (Fig. S31-34) is decreased in comparison to $\mathbf{5 E u}$ or $\mathbf{5 Y b}$ ( 28 and $15 \%$, respectively) and is still observed after one week. It is weaker than that observed upon oxidation of the previously reported tripodal pro-radical complexes, ${ }^{23-25}$ but yet unambiguously detectable and consistent with early results on lanthanide-nitroxide molecular solids. ${ }^{40}$ It is remarkable that the stability of the radical product is much higher than in tripodal complexes, ${ }^{9}$ which decompose above $273 \mathrm{~K}$, thereby precluding their use in biological imaging. Hence the fact that a change in luminescence is observed in the present case is encouraging for the design of future ROS-responsive lanthanide complexes.

In conclusion we designed a dual-mode probe based on a pronitroxide lanthanide complex. It reacts with $\mathrm{OH}^{\bullet}$ to give stable lanthanide radical complexes that are detectable by EPR spectroscopy and whose metal-based luminescence (Visible or NIR) experiences a detectable quenching upon oxidation. The nitronyl nitroxide moiety, which is the radical ultimately formed in the reaction with $\mathrm{OH}^{*}$, belongs to the well-known family of nitric oxide traps. The detection in the latter case is based on the conversion of the nitronyl nitroxide into an $\alpha$ iminonitroxide radical in the presence of $\mathrm{NO}$ (reactive nitrogen species RNS). ${ }^{41,}{ }^{42}$ Alternatively we herein demonstrate that the nitronyl nitroxide radical can be the final product and the $\alpha$-iminonitroxide radical is a transient species upon reaction of $\mathbf{5} \mathbf{L n}$ with ROS like $\mathrm{OH}^{\circ}$. These results reveal an unprecedented behaviour and illustrate the intricacy of the design of biological spin traps since $\mathrm{NO}$ is a major messenger that interacts with 
ROS in living organisms to produce peroxynitrite, an inducer of cell death. ${ }^{43}$

\section{Acknowledgements}

This work is supported by the French National Research Agency in the framework of the "Investissements d'avenir" program (ANR-15-IDEX-02), Labex ARCANE, CBH-EUR-GS (ANR17-EURE-0003) and ANR Co-Lhanta (ANR-13-BOS08-0011-01).

\section{Notes and references}

\# General procedure for the synthesis of the complexes: The ligand 5 was dissolved in water $(10 \mathrm{~mL})$ and the lanthanide salt was added to the solution. The $\mathrm{pH}$ was adjusted to 7 by addition of sodium hydroxide $(0.5 \mathrm{M})$. The reaction mixture was stirred and heated to $50^{\circ} \mathrm{C}$ overnight. The reaction is stirred until the $\mathrm{pH}$ of the solution stopped decreasing and water is removed from the reaction by evaporation. Purification by exclusion chromatography LH-20 Sephadex gives the desired compound $\mathbf{5 L n}$ as a bright yellow powder. $\mathbf{5 Y b}$ : From $\mathbf{5}$ (30 mg, $0.052 \mathrm{mmol})$ and ytterbium nitrate $(24 \mathrm{mg}, 0.052 \mathrm{mmol})$. Yield: $30.8 \mathrm{mg}$ (81\%). HR-MS m/z calcd for $\mathrm{C}_{27} \mathrm{H}_{41} \mathrm{O}_{7} \mathrm{~N}_{7} \mathrm{Yb}[\mathrm{M}+\mathrm{H}]^{+}, 749.2455$ found $749.2447 . \mathrm{IR}\left(\mathrm{cm}^{-1}\right)$ : 3390, 3246, 2990, 2879, 1593, 1318, 1202, 1134, 1083, 1001, 941, 831, 799, 713. 5Eu: From 5 (30 mg, $0.052 \mathrm{mmol}$ ) and europium nitrate $(24 \mathrm{mg}, 0.052 \mathrm{mmol})$. Yield: $11.0 \mathrm{mg}$ (29\%). ${ }^{1} \mathrm{H}$ NMR (400 MHz, $\left.\mathrm{D}_{2} \mathrm{O}\right) \mathrm{\delta} / \mathrm{ppm}$ 12.80, 11.17, $9.81,9.62,9.48,3.94,3.59-3.21(\mathrm{~m}), 2.25,2.13(\mathrm{~d}), 1.45-1.18$ (m), $0.34,-0.78,-2.19,-2.95,-3.25,-3.48,-3.70,-7.10,-8.07$, $10.11,-11.63$ (d) $12.23,-12.83,-13.51$. HR-MS $\mathrm{m} / \mathrm{z}$ calcd for $\mathrm{C}_{27} \mathrm{H}_{41} \mathrm{O}_{7} \mathrm{~N}_{7} \mathrm{Eu}[\mathrm{M}+\mathrm{H}]^{+}, 728.2277$ found 728.2265 . IR $\left(\mathrm{cm}^{-1}\right)$ : 3379, $3259,2980,2870,1587,1448,1394,1320,1239,1085,1005$, $935,906,837,717$.

1. N. R. Gough, Sci. Sign., 2009, 2, eg12.

2. B. C. Dickinson and C. J. Chang, Nat. Chem. Biol., 2011, 7, 504-511.

3. H. Sies, C. Berndt and D. P. Jones, Annu. Rev. Biochem, 2017, 86, 715-748.

4. P. Storz, Sci. STKE, 2006, 2006, re3.

5. I. I. C. Chio and D. A. Tuveson, Trends Mol. Med., 2017, 23 411-429.

6. N. Houstis, E. D. Rosen and E. S. Lander, Nature, 2006 440, 944-948.

7. F. Collin, Int. J. Mol. Sci., 2019, 20, 2407.

8. N. Panth, K. R. Paudel and K. Parajuli, Adv. Med., 2016, 2016, 12

9. F. A. Villamena, in Reactive Species Detection in Biology, ed. F. A. Villamena, Elsevier, Boston, 2017, pp. 163-202.

10. X. Chen, X. Tian, I. Shin and J. Yoon, Chem. Soc. Rev., 2011, 40, 4783-4804.

11. X. Wang, H. Fang, Z. Huang, W. Shang, T. Hou, A. Cheng and H. Cheng, J. Mol. Med., 2013, 91, 917-927.

12. J. F. Woolley, J. Stanicka and T. G. Cotter, Trends Biochem. Sci, 2013, 38, 556-565.

13. D. Parker, R. A. Poole and F. Kielar, 2006, WO2008007089.

14. B. Song, G. Wang, M. Tan and J. Yuan, J. Am. Chem. Soc., 2006, 128, 13442-13450.

15. G.-L. Law, R. Pal, L. O. Palsson, D. Parker and K.-L. Wong, Chem. Commun., 2009, 7321-7323.

16. A. R. Lippert, T. Gschneidtner and C. J. Chang, Chem Commun., 2010, 46, 7510-7512.
17.

20.

21.

23.

24.

25.

26

26.

27.

28.

29.

30.

31.

32.

33.

34.

35.

36.

37.

38.

39.

40.

41.

42. J. Wang, C. He, P. Wu, J. Wang and C. Duan, J. Am. Chem Soc., 2011, 133, 12402-12405

43. C. Szabó, H. Ischiropoulos and R. Radi, Nat. Rev. Drug Disc., 2007, 6, 662-680. 
View Article Online DOI: 10.1039/C9CC06524E 

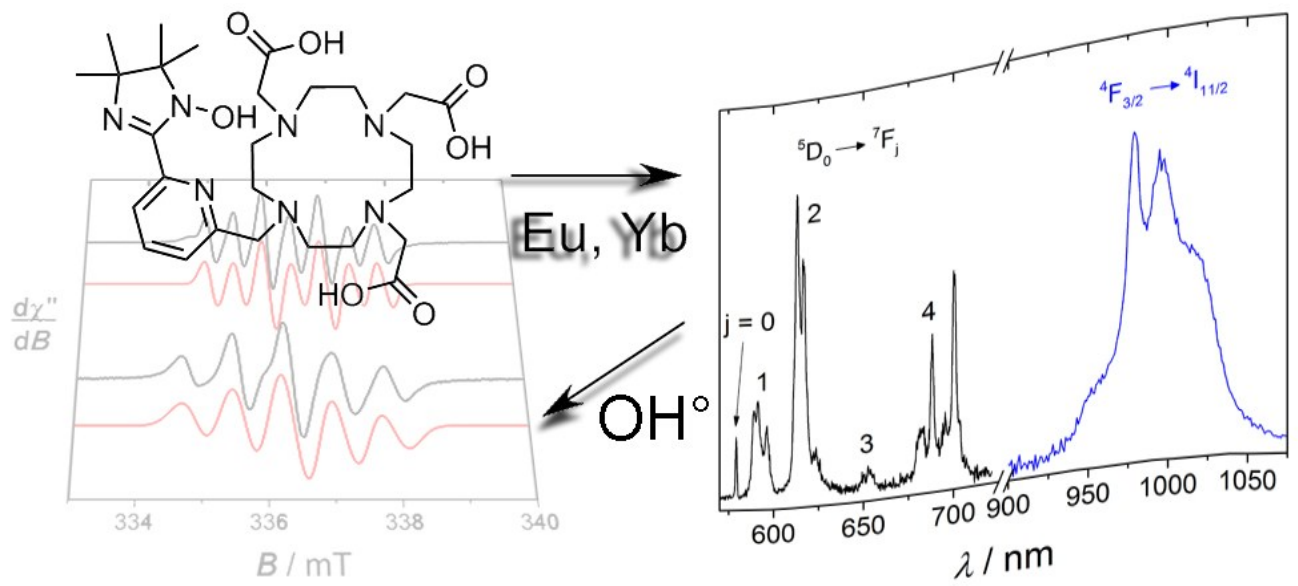

$82 \times 37 \mathrm{~mm}(300 \times 300 \mathrm{DPI})$ 